\title{
Lecture critique
}

\section{Christophe Clivaz, Stéphane Narath et Mathis Stock (dir.), Tourisme, urbanité, durabilité}

Revue Urbia - Les Cahiers du développement urbain durable, $\mathrm{n}^{\circ} 10$, Observatoire universitaire de la ville et du développement durable, juin 2010, 140 pages

\section{Philippe Duhamel}

\section{(2) OpenEdition}

\section{Journals}

Édition électronique

URL : http://journals.openedition.org/tourisme/484

DOI : 10.4000/tourisme.484

ISSN : 2492-7503

Éditeur

Éditions touristiques européennes

Édition imprimée

Date de publication : 1 décembre 2011

Pagination : 112-113

ISSN : 2109-5671

Référence électronique

Philippe Duhamel, « Christophe Clivaz, Stéphane Narath et Mathis Stock (dir.), Tourisme, urbanité, durabilité », Mondes du Tourisme [En ligne], 4 | 2011, mis en ligne le 30 septembre 2015, consulté le 22 septembre 2020. URL : http://journals.openedition.org/tourisme/484 ; DOI : https://doi.org/10.4000/ tourisme.484

Ce document a été généré automatiquement le 22 septembre 2020.

\section{(1) $\$$}

Mondes du tourisme est mis à disposition selon les termes de la licence Creative Commons Attribution - Pas d'Utilisation Commerciale - Pas de Modification 4.0 International. 


\section{Lecture critique}

\section{Christophe Clivaz, Stéphane Narath et Mathis Stock (dir.), Tourisme, urbanité, durabilité}

Revue Urbia - Les Cahiers du développement urbain durable, $\mathrm{n}^{\circ} 10$, Observatoire universitaire de la ville et du développement durable, juin 2010, 140 pages

\section{Philippe Duhamel}

\section{RÉFÉRENCE}

Christophe Clivaz, Stéphane Narath et Mathis Stock (dir.), Tourisme, urbanité, durabilité, revue Urbia - Les Cahiers du développement urbain durable, $\mathrm{n}^{\circ} 10$, Observatoire universitaire de la ville et du développement durable, juin 2010.

1 Christophe Clivaz, Stéphane Narath et Mathis Stock, professeurs à l'Institut Kurt Bösch de Sion, haut lieu de la recherche en tourisme en Suisse, nous proposent un numéro thématique rassemblant six contributions. L'enjeu et la "particularité" de ce recueil d'articles sont très clairement explicités dès le début : "aborder la question de la durabilité du tourisme dans les lieux marqués par l'urbanité". Dès lors, l'urbanité ne sera pas un thème d'analyse, ce que nous regrettons.

2 La lecture de l'ensemble apparaît bipartite: trois textes évoquent la question de l'espace urbain et de ses évolutions à travers les exemples de Barcelone, Genève et du quartier touristique Waïkiki, à Honolulu; les trois textes suivants abordent davantage la problématique des stations.

3 Dans tous les articles, un réel effort est fait pour établir la relation entre durabilité et tourisme. Dans tous sont proposés nombre d'informations et de références permettant de parfaire sa culture sur des lieux, comme Genève, "angle mort" courant de notre culture géographique française. Mais on regrettera que l'investissement descriptif et 
informatif des auteurs ne soit pas suivi d'une analyse aussi importante. Par exemple, les auteurs des deux premiers articles décrivent des évolutions à Barcelone ou à Genève, mais n'apportent pas leur regard scientifique à la compréhension des processus. Ce sentiment s'atténue par la suite avec le texte sur Waïkiki qui, plus original par son terrain, nous permet d'aborder un lieu original. Les deux contributions de Christophe Clivaz (dont une en co-rédaction) sont elles aussi descriptives, mais la comparaison entre différents modèles nationaux introduit un élément nouveau d'originalité. Là, à notre grande stupéfaction, le(s) auteur(s) montre(nt) les "qualités" du modèle français qui, en matière de procédures d'aménagement "respectueuses" du développement durable ou de prise en compte des saisonniers, est bien plus performant que les modèles suisse et italien. En cela, nous ne saurions trop en recommander la lecture. Enfin, la dernière contribution, bien qu'intéressante, apparait "décalée" au regard de l'ensemble du numéro thématique. Elle porte sur les Régimes institutionnels de ressources (RIR) liés à la problématique de l'eau. Y est abordée une question primordiale des stations et la réflexion proposée, en cours de réalisation puisqu'il s'agit d'une thèse, est toujours digne d'une lecture.

4 Au final, un numéro informé avec une entrée double qui montre la difficulté des numéros thématiques. Sans doute s'agit-il d'un premier pas, pour amorcer une réflexion que les auteurs-directeurs poursuivront. Sans doute la plus grande cohérence d'un tel projet aurait-elle résidé dans une plus grande mise en perspective des articles. Cela fut entrepris par les auteurs-directeurs en pages 8-9, insuffisamment. 